\title{
BMJ open Assessing community health workers' performance motivation: a mixed-methods approach on India's Accredited Social Health Activists (ASHA) programme
}

\author{
Saji Saraswathy Gopalan, ${ }^{1}$ Satyanarayan Mohanty, ${ }^{2}$ Ashis Das ${ }^{1}$
}

To cite: Gopalan SS, Mohanty S, Das A. Assessing community health workers' performance motivation: a mixed-methods approach on India's Accredited Social Health Activists (ASHA) programme. BMJ Open 2012;2:e001557. doi:10.1136/bmjopen-2012001557

- Prepublication history and additional material for this paper are available online. To view these files please visit the journal online (http:// dx.doi.org/10.1136/bmjopen2012-001557).

Received 24 May 2012 Accepted 15 August 2012

This final article is available for use under the terms of the Creative Commons Attribution Non-Commercial 2.0 Licence; see http://bmjopen.bmj.com

\footnotetext{
${ }^{1}$ The World Bank, NW Washington DC, USA ${ }^{2}$ DCOR Consulting Pvt Ltd, Bhubaneswar, Orissa, India
}

Correspondence to Dr Saji Saraswathy Gopalan; sajisaraswathyg@gmail.com

\section{ABSTRACT}

Objective: This study examined the performance motivation of community health workers (CHWs) and its determinants on India's Accredited Social Health Activist (ASHA) programme.

Design: Cross-sectional study employing mixedmethods approach involved survey and focus group discussions.

Setting: The state of Orissa.

Participants: $386 \mathrm{CHWs}$ representing $10 \%$ of the total $\mathrm{CHWs}$ in the chosen districts and from settings selected through a multi-stage stratified sampling.

Primary and secondary outcome measures: The level of performance motivation among the CHWs, its determinants and their current status as per the perceptions of the CHWs.

Results: The level of performance motivation was the highest for the individual and the community level factors (mean score 5.94-4.06), while the health system factors scored the least (2.70-3.279). Those ASHAs who felt having more community and system-level recognition also had higher levels of earning as CHWs $(\mathrm{p}=0.040$, $95 \% \mathrm{Cl} 0.06$ to 0.12 ), a sense of social responsibility ( $p=0.0005,95 \% \mathrm{Cl} 0.12$ to 0.25 ) and a feeling of selfefficacy ( $\mathrm{p}=0.000,95 \% \mathrm{Cl} 0.38$ to 0.54 ) on their responsibilities. There was no association established between their level of dissatisfaction on the incentives $(p=0.385)$ and the extent of motivation. The inadequate healthcare delivery status and certain working modalities reduced their motivation. Gender mainstreaming in the community health approach, especially on the demandside and community participation were the positive externalities of the $\mathrm{CHW}$ programme.

Conclusions: The CHW programme could motivate and empower local lay women on community health largely. The desire to gain social recognition, a sense of social responsibility and self-efficacy motivated them to perform. The healthcare delivery system improvements might further motivate and enable them to gain the community trust. The CHW management needs amendments to ensure adequate supportive supervision, skill and knowledge enhancement and enabling working modalities.

\section{ARTICLE SUMMARY}

Article focus

- What is the current level of the performance motivation of the community health workers?

- What are the determinants of their performance motivation?

- What are the community health workers' (CHWs) perceptions and experiences on the current status of the factors affecting their performance motivation?

Key messages

- The CHWs are more motivated on the individual and the community level factors than the health system determinants.

- The qualitative findings also support the survey outcomes that the healthcare delivery status and the human resource management modalities for $\mathrm{CHW}$ are not satisfactory for them.

- This study recommends that the CHW management needs changes to ensure adequate supportive supervision, skill and knowledge enhancement and enabling working modalities.

Strengths and limitations of this study

- This is a unique study exploring the performance motivation of the public sector CHW on one of the largest CHW programmes in the world. The evidence on CHWs' performance motivation and that of public sector $\mathrm{CHW}$ programmes are limited. The unique application of the mixed-methods approach will enhance the generalisability of the study findings. It helped in finding the causality between the level of CHW's motivation and its each determinant along with an understanding of how and why a CHW is motivated or demotivated. The study discussions are centred on comparable global experiences for relevant policy changes.

- Among the study limitations, there could be a possibility of CHWs' responses complying with perceptions of what should be an acceptable answer. We did not assess the actual level of performance of the CHWs and its effectiveness from the community's or the supervisors' perspectives. 


\section{INTRODUCTION}

Globally, the intermediation of community health workers (CHWs) in healthcare delivery is widening as they are inevitable to meet the universal healthcare provision and the millennium development goals. ${ }^{1}$ The term 'community health worker' encompasses a wide variety of local healthcare providers ranging from nurse-midwives to home-based care givers and salaried-staffs to volunteers. ${ }^{2}$ The CHWs enable access to and utilisation of health services, and inculcate healthy behaviours among the communities. ${ }^{3}$ They are preponderantly deployed to cater to underutilised services, unmet health behaviours and underserved populations. ${ }^{3}$ The CHW's contributions to disease control, immunisation and family planning programmes are already established. ${ }^{4}$ In the public sector, though the CHWs are primarily link-workers or motivators, yet they do undertake curative services for malaria, tuberculosis and elderly care. ${ }^{3}$ The spectrum of the CHW programmes varies across countries on their objectives, rollout and management. Their larger penetration and sustainability are more observed with the public sector. ${ }^{5}$ Having identified the potential of women in community mediation, predominantly females constitute CHWs universally. ${ }^{2}$

\section{Rationale}

The existing literature on CHWs' performance motivation and its determinants are scanty. Similar to any other health cadre, the performance of CHWs depends on their job satisfaction derived from certain intrinsic and extrinsic motivators. ${ }^{6}$ However, the yardstick for their performance motivation assessment should be different from usual health staffs particularly on three grounds; (1) many CHWs are volunteers and not salaried staff, (2) they are lay workers without prior training on community health and (3) CHWs constitute the outreach workforce directly linking the community with the formal healthcare. Further, the approach to assess the public sector CHWs' work motivation could be different from the private sector since they are more integrated with the formal healthcare system and have wider responsibilities. The existing few studies from Kenya, Vietnam, Bangladesh, Taiwan, etc have largely catered to the latter or omitted a 'mixed -methods approach' by mostly employing the qualitative tools. $^{8-12}$ This paper explores one of the largest public sector community health worker initiatives in the world, namely the Accredited Social Health Activist (ASHA) programme in India. This study had three objectives: (1) assessing the current level of performance motivation among the ASHAs, (2) understanding the factors affecting their level of motivation and (3) their perceptions and experiences on the current status of the motivational determinants.

\section{ASHA programme: an overview}

The ASHA is a female volunteer selected by the community, deployed in her own village (one in every 1000

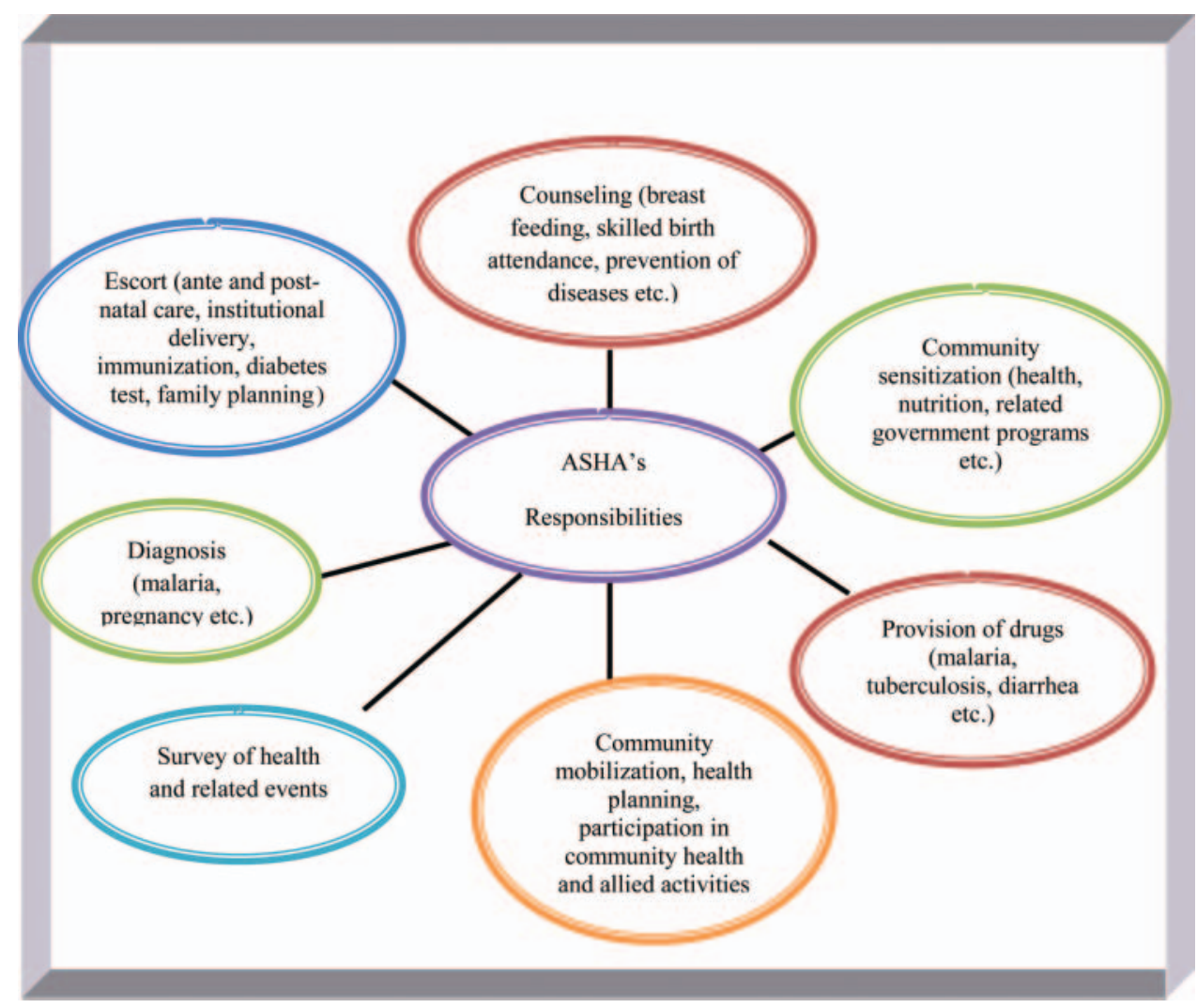

Figure 1 Responsibilities of the Accredited Social Health Activist. 
population) after a short training on community health. ${ }^{13}$ She is preferred to be between 25 and 45 years old, with a minimum formal education of 8 years and demonstrable leadership qualities. ${ }^{13}$ ASHAs are not salaried and they belong to the voluntary cadre of health staffs as they get fixed activity-based incentives. Started in 2006, currently the ASHA programme has spread across the country with 820000 women trained and deployed. ${ }^{14}$ Their responsibilities range from health education to diagnosis of health conditions (figure 1). Each state oversees the programme confining to the guidelines of the National Rural Health Mission (NRHM).

\section{METHODS}

\section{Conceptual framework}

The concept of 'performance motivation' is complex and can be defined contextually. The study defined it as the CHW's degree of interest and willingness to undertake and improve upon an allotted responsibility towards community health. ${ }^{8}$ We used a customised framework adapted from the existing literature. ${ }^{8-12}{ }^{15}{ }^{16}$ The motivation factors were broadly classified into individual and environmental. The latter was further divided into health system and community level factors (figure 2). Further, 16 parameters were considered (identified from the literature and selfvalidated by the CHWs through group discussions) together under the above broad classifications, that is, individual, health system and community levels (table 2).

\section{Assessment tools}

This cross-sectional study conducted during 2010 employed a mixed-methods approach, that is, a combination of qualitative and quantitative techniques. It employed both survey and focus groups discussions among the CHWs. The survey tool constituted 16 parameters and under each a set of questions explored their level of motivation on a Likert scale of 1 (strongly disagree) to 5 (strongly agree). The construct of the questions were balanced with both positive and negative directions to prevent similar responses. The composite score of all questions decided the level of motivation under each parameter. A CHW was considered as motivated on a particular parameter if her mean score was above 3. At the health system level, the exploration was on the organisation and management of the healthcare delivery system (eg, availability of services and commodities, incentives, monitoring and training of CHWs, interaction with supervisors, peers and grass roots nongovernmental organisations (NGOs)). The community level parameters consisted of community response, recognition of CHW and participation in activities. At the individual level, abilities, inducements to perform, job satisfaction, family support, etc were explored. The focus group discussions (FGDs) explored CHWs' current experiences and perceptions on the factors affecting their performance motivation. Their suggestions to improve upon the existing situations were also probed.

\section{Sampling and recruitment}

The study settings were selected through a multistage stratified sampling. First, Orissa was selected randomly among the high-focus states of NRHM. Then, the districts of Angul and Mayurbhanj were selected representing the state based on its administrative division. Finally, $25 \%$ of the rural administrative blocks from each district were randomly selected.

The survey purposively targeted $10 \%(n=434)$ of the existing number of ASHAs $(n=4342)$ together from both the districts. ${ }^{7}$ Thus, it planned to interview 55 ASHAs from each of the eight rural administrative blocks.

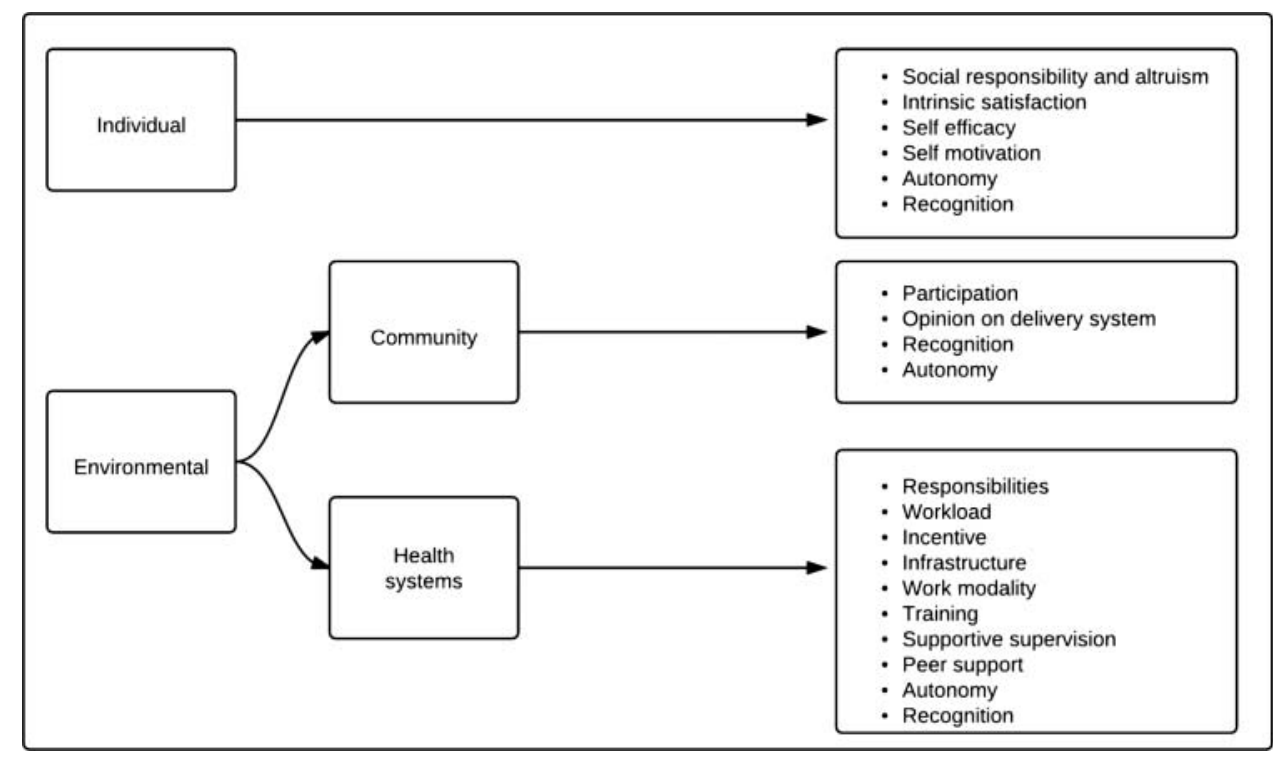

Figure 2 Community health worker's performance motivation assessment framework. 
Table 1 Background characteristics of the $\mathrm{CHWs}$

\begin{tabular}{|c|c|}
\hline Characteristics & Percentage (n/386) \\
\hline \multicolumn{2}{|l|}{ Age (years) } \\
\hline $25-30$ & $45.60(176)$ \\
\hline $31-35$ & $32.64(126)$ \\
\hline $36-40$ & $17.88(69)$ \\
\hline$>41$ & $3.88(15)$ \\
\hline \multicolumn{2}{|l|}{ Education (years) } \\
\hline $5-7$ & $14.25(55)$ \\
\hline $8-10$ & $85.75(331)$ \\
\hline \multicolumn{2}{|l|}{ Marital status } \\
\hline Married & $70.47(272)$ \\
\hline Widowed & $17.88(69)$ \\
\hline Separated & $3.88(15)$ \\
\hline Unmarried & $4.92(19)$ \\
\hline Divorced & $2.85(11)$ \\
\hline \multicolumn{2}{|l|}{ Poverty status } \\
\hline Below poverty line & $70.98(274)$ \\
\hline Above poverty line & $29.02(112)$ \\
\hline \multicolumn{2}{|c|}{ Monthly household income in INR (US\$) } \\
\hline $1000-2000(22.21-44.44)$ & $21.51(83)$ \\
\hline $2001-3000(44.46-66.65)$ & $43.26(167)$ \\
\hline$>3000(66.67)$ & $35.23(136)$ \\
\hline \multicolumn{2}{|l|}{ Caste } \\
\hline Scheduled caste* & $29.02(112)$ \\
\hline Scheduled tribe* & $36.01(139)$ \\
\hline Others & $34.97(135)$ \\
\hline \multicolumn{2}{|c|}{ Monthly earning as $\mathrm{CHW}$ in INR (US\$) } \\
\hline$<500(11.13)$ & $2.07(8)$ \\
\hline $500-1000(11.13-22.21)$ & $14.77(57)$ \\
\hline $1001-1500$ (22.24-33.33) & $83.16(321)$ \\
\hline \multicolumn{2}{|l|}{ Sources of earning } \\
\hline Only as $\mathrm{CHW}$ & $91.97(355)$ \\
\hline Other sources & $8.03(31)$ \\
\hline \multicolumn{2}{|l|}{ Years of experience as ASHA } \\
\hline$<2$ & $17.10(66)$ \\
\hline $2-5$ & $82.90(320)$ \\
\hline \multicolumn{2}{|l|}{ Number of trainings undergone } \\
\hline$<5$ & $73.06(282)$ \\
\hline $6-10$ & $26.94(104)$ \\
\hline
\end{tabular}

${ }^{*}$ Scheduled caste and tribe are communities that receive special privileges from the Government of India based on relatively weaker socio-economic status.

ASHA, Accredited Social Health Activist; CHWs, community health workers; INR, Indian rupees.

However, only 386 ASHAs could be interviewed considering their availability and willingness during the study period. Each survey on an average took about 30-45 min.

There were 11 FGDs for 78 CHWs and each constituted 7-10 participants. There were mixed groups of ASHAs from different socio-economic and demographic backgrounds. Each FGD took between 45 and $60 \mathrm{~min}$ and interviews were conducted till the data saturation. An FGD guide with broad themes and specific probes directed the discussions. The FGDs were conducted first, followed by the survey.

The local women's groups mobilised the CHWs for the surveys and the FGDs. The interviews were conducted in the local language Oriya. The participants were informed about this study through local village leaders and women's groups a week prior to the study. A written informed consent was obtained from each CHW after explaining the study objectives and the intended use of the information. The participation was completely voluntary and the respondents had the choice of not answering any question or withdrawal from the study at any time. The confidentiality of the participants was maintained throughout the study. The interviews were conducted at a convenient location and refreshments were provided to the participants. In each district, the survey and the FGDs were performed by five locally based researchers, who were social science bachelors. The entire data collection process took 3 months. A predesigned protocol guided the conduct of the data collection and further, it was supervised by one of the coauthors. We could not initiate for ethical approval as there was no such specific entity in the state providing ethical approval on this kind of research.

\section{Data analysis}

The quantitative information was analysed through STATA. Linear and multivariate regression tests explored the association between the level of performance motivation and the predictors at different levels along with the CHWs' background characteristics. The qualitative data were transcribed verbatim and translated to English by the researchers themselves who conducted the interviews. These translations were verified by the coauthors who are proficient in the local language. The translated transcripts were coded and analysed through NVivo. The analysis was both inductive and deductive and relevant themes were indexed under the individual, health system and community-level aspects. They were further classified as the enabling and the demotivating factors for the CHW's performance. The qualitative findings were triangulated with the survey findings confining to the conceptual framework of the study.

\section{RESULTS}

The survey consisted of 386 CHWs (table 1), of which the majority were below poverty line $(71 \%)$, married $(70.47 \%)$ and scheduled tribes $(36 \%)$. Most of them had 8 years of formal education $(85.75 \%)$, experience of $2-5$ years as CHW $(82.9 \%)$. The majority had undergone a minimum five trainings $(73.06 \%)$, earned US $\$ 22.24-33.33 /$ month as a CHW $(83.16 \%)$. Further, most of them did not have any other personal sources of earning $(91.97 \%)$.

\section{Level of performance motivation among the CHWs}

The level of motivation was the highest on the intrinsic job satisfaction on various job-related achievements (mean $4.30 ; 68.4 \%$ of CHWs). The self-efficacy or the perceived abilities on job scored a mean score of 4.27 (69.7\%). 
Table 2 Level of performance motivation among the community health workers (CHWs) (N=386)

\begin{tabular}{|c|c|c|c|}
\hline Variable & Mean & $95 \% \mathrm{Cl}$ & $\begin{array}{l}\text { Motivated* } \\
\text { n (\%) }\end{array}$ \\
\hline \multicolumn{4}{|l|}{ Health system level } \\
\hline $\begin{array}{l}\text { Nature of responsibilities: level of interest in the responsibilities } \\
\text { and confidence to execute them }\end{array}$ & 4.18 & 4.09 to 4.27 & $256(66.3)$ \\
\hline $\begin{array}{l}\text { Workload: time to complete daily tasks, able to spend time with } f \\
\text { amily and flexibility in work schedule }\end{array}$ & 2.96 & 2.90 to 3.02 & $34(8.8)$ \\
\hline $\begin{array}{l}\text { Incentive: adequacy of financial and non-financial incentives and their } \\
\text { pattern of payment }\end{array}$ & 3.07 & 2.97 to 3.17 & $64(16.6)$ \\
\hline $\begin{array}{l}\text { Healthcare infrastructure: satisfaction on the quality of existing infrastructure, } \\
\text { communication options and commodities }\end{array}$ & 2.83 & 2.78 to 2.89 & $26(6.7)$ \\
\hline $\begin{array}{l}\text { Work modality: satisfaction on hierarchy, participatory approach, } \\
\text { recording and reporting }\end{array}$ & 3.18 & 3.13 to 3.24 & $68(17.6)$ \\
\hline $\begin{array}{l}\text { Training: level of knowledge and skills imparted through trainings, and timing and } \\
\text { organisation of training }\end{array}$ & 3.78 & 3.72 to 3.85 & $281(72.8)$ \\
\hline $\begin{array}{l}\text { Supportive supervision: help, monitoring, and supervision to execute } r \\
\text { esponsibilities and solve issues }\end{array}$ & 3.28 & 3.23 to 3.32 & $47(12.2)$ \\
\hline $\begin{array}{l}\text { Peer support: moral support, advice and learning from peers } \\
\text { Community level }\end{array}$ & 4.04 & 3.95 to 4.14 & $298(77.2)$ \\
\hline $\begin{array}{l}\text { Community participation: level of community's interest, acceptance and } \\
\text { participation in activities }\end{array}$ & 4.05 & 3.96 to 4.16 & $244(63.2)$ \\
\hline $\begin{array}{l}\text { Community opinion on public healthcare system: on quality of care, availability of } \\
\text { healthcare and community programmes } \\
\text { Individual level }\end{array}$ & 2.70 & 2.65 to 2.75 & $4(1.0)$ \\
\hline Social responsibility and altruism: interest in social work when existing & 4.12 & 4.04 to 4.20 & $255(66.1)$ \\
\hline $\begin{array}{l}\text { social norms adversely impact community health, and sense of social responsibility } \\
\text { Intrinsic job satisfaction: chance for better use of abilities and time, feeling of } \\
\text { accomplishment, awards, career enhancement, advancement in employability, } \\
\text { knowledge, communication skills, managerial skills and overall happiness being on job }\end{array}$ & 4.30 & 4.24 to 4.36 & $264(68.4)$ \\
\hline $\begin{array}{l}\text { Self-efficacy: able to handle tough situations, solve problems, feel emotionally and } \\
\text { physically perfect on work }\end{array}$ & 4.27 & 4.20 to 4.33 & $269(69.7)$ \\
\hline $\begin{array}{l}\text { Self-motivation: working with a sense that the job is important and is not for } \\
\text { avoiding blame from others and gaining money alone } \\
\text { Individual+community+health system level }\end{array}$ & 4.07 & 4.05 to 4.10 & $327(84.7)$ \\
\hline $\begin{array}{l}\text { Recognition: acceptance of CHWs' performance, its value, and talents by family, } \\
\text { community and system }\end{array}$ & 3.96 & 3.90 to 4.02 & $214(55.4)$ \\
\hline $\begin{array}{l}\text { Autonomy: freedom to move in the community, express opinion and execute } \\
\text { responsibilities }\end{array}$ & 3.96 & 3.90 to 4.02 & $233(60.4)$ \\
\hline
\end{tabular}

${ }^{*}$ Motivated if mean score $>3$.

The nature of the job responsibilities positioned at the third with a mean score of $4.18(66.3 \%)$, followed by the social responsibility and altruism $(4.12 ; 66.1 \%)$. The mean scores were 4.07 for the self-motivation $(84.7 \%)$, 4.06 for the community participation in activities $(63.2 \%)$ and 4.04 for the peer support $(77.2 \%)$.

The degree of motivation was the least on the community opinion on the healthcare delivery system $(2.7 ; 1 \%)$, followed by their satisfaction on the level of healthcare infrastructure $(2.83 ; 6.7 \%)$. The ASHAs were also less motivated on their work load $(2.96 ; 8.8 \%)$. They had a moderate level of motivation (mean 3-4) on enjoying the autonomy to move, express opinions and execute the responsibilities $(3.96 ; 60.4 \%)$. The recognition from the community, family and health system scored moderately $(3.96 ; 55.4 \%)$. The training $(3.78 ; 72.8 \%)$, the type of supportive supervision received $(3.28 ; 12.2 \%)$, the work modality $(3.18 ; 17.6 \%)$ and the incentives $(3.07 ; 16.6 \%)$ also scored a moderate mean.

A large proportion of the ASHAs ( $n=327 ; 84.72 \%)$ were self-motivated. If we look at the individual scores for each parameter, the question on community acceptance, that is, the community accepts my activities as $I$ intend to secured the highest mean score at 4.64 $(\mathrm{n}=366)$. Second, a self-efficacy-related question (I can always manage to solve difficult problems if I try hard enough) scored at $4.58(\mathrm{n}=350)$. Further, the probe on the intrinsic job satisfaction (I am satisfied that I accomplish something worthwhile in this job) received a mean score of $4.54(\mathrm{n}=336)$.

As per the Cronbach's $\alpha$ test, the internal consistency of the scale was adequate. The consistency coefficient was $0.78,0.79$ and 0.84 for the community, health system and the individual scales, respectively. 
Determinants of the level of performance motivation

The ASHA's earning as a CHW ( $\mathrm{p}<0.05,95 \%$ CI 0.06 to $0.12)$, sense of social responsibility and altruism $(\mathrm{p}<0.01$, 95\% CI 0.12 to 0.25$)$ and feeling of self-efficacy $(\mathrm{p}<0.01$, $95 \%$ CI 0.38 to 0.54 ) in undertaking responsibilities influenced her recognition at the health system, community and family (not mentioned in the tables). Other socio-economic characteristics were not significant in this regard.

\section{How does the healthcare delivery system impact on the} CHW's level of motivation?

We explored how significantly the level of motivation on the health system factors influenced their motivation at the individual and the community levels. This exploration was prompted by the fact that the CHWs were more demotivated on the status of the former (table 2 and figure 3). The peer support induced for a higher level of satisfaction on the community participation, recognition, selfefficacy and intrinsic job satisfaction. On the contrary, the dissatisfaction on the workload also led to a higher level of dissatisfaction on the above aspects. The dissatisfied CHWs on the supportive supervision had reported a lesser community recognition and intrinsic job satisfaction. The demotivation on the work modality and the healthcare infrastructure were positively related to a lesser intrinsic job satisfaction. Their perceptions on the incentives did not affect the level of motivation on any of the community, individual or health system parameters (table 3).

\section{Prevailing scenario of the factors affecting the} performance motivations: experiences of the ASHAs Enabling factors

The better use of time (91\%), lack of alternative job opportunities $(76 \%)$ and a sense of social responsibility $(68 \%)$ were the reasons to become a CHW and everyone wanted to continue as ASHA. They considered performance motivation as an encouragement $(45 \%)$ or something which makes their performance better (62\%). Their prior involvement in women's groups improved their sense of altruism. Working with the community as CHW and empowering them, especially women, inspired many. They felt women to be more receptive to their health advices and engage in community activities compared to men.

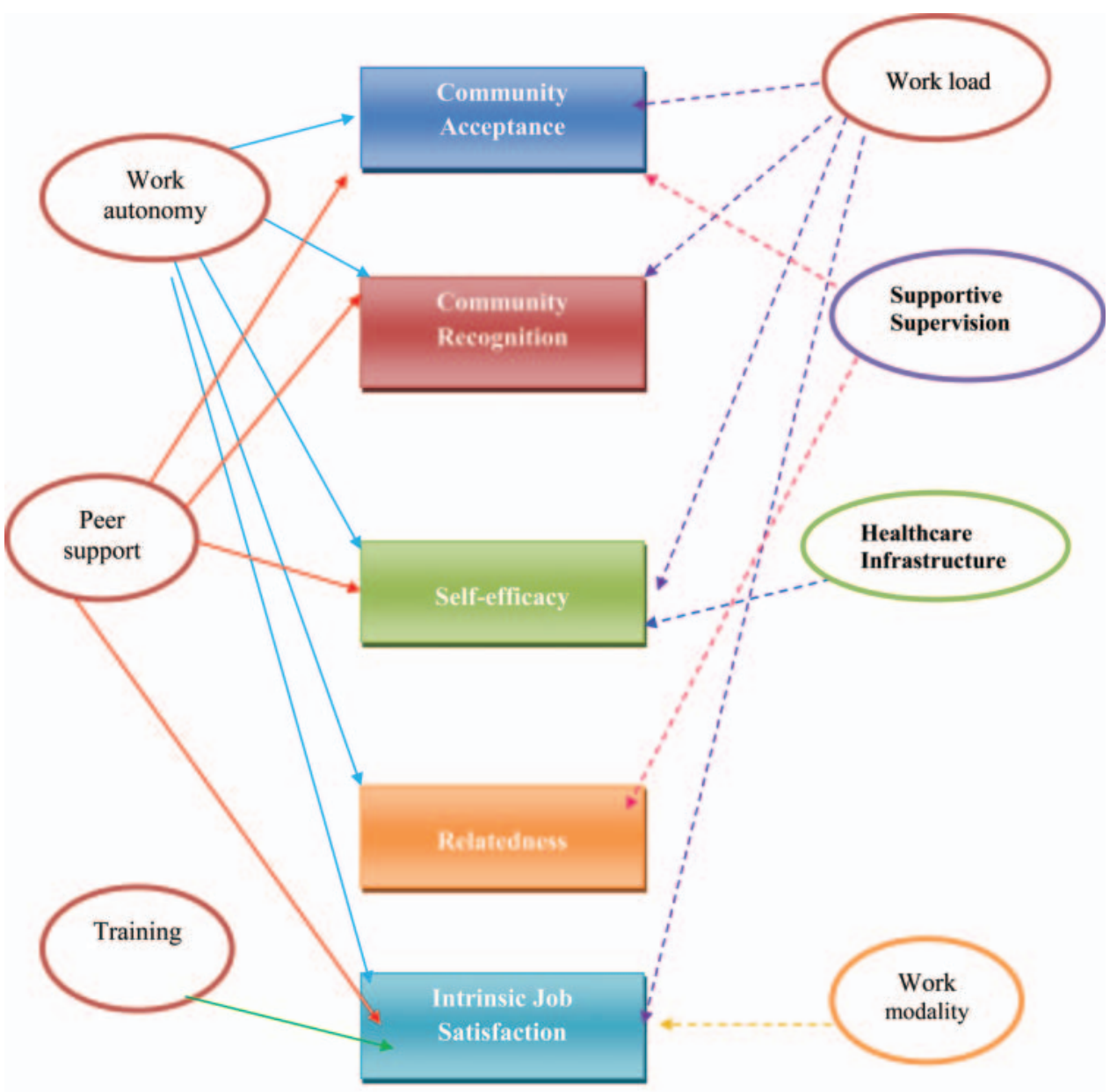

(Solid arrows indicate enabling relationship and dotted arrows indicate deterring relationship)

Figure 3 Healthcare delivery system vis-à-vis the community health workers' performance motivation. 
Table 3 Influence of the healthcare delivery system on the community health workers' (CHWs) performance motivation

\begin{tabular}{|c|c|c|c|c|c|c|}
\hline Dependent variable & Independent variable & Coefficient & SE & p Value & $95 \% \mathrm{Cl}$ & $\mathbf{R}^{2}$ \\
\hline \multirow[t]{3}{*}{ Community participation } & Work load & -0.065 & 0.028 & $<0.05$ & -0.12 to -0.01 & 0.069 \\
\hline & Work autonomy & 0.062 & 0.026 & $<0.01$ & 0.01 to 0.11 & \\
\hline & Peer support & 0.139 & 0.049 & $<0.001$ & 0.04 to 0.24 & \\
\hline \multirow[t]{4}{*}{ Community recognition } & Work load & -0.215 & 0.077 & $<0.001$ & -0.37 to -0.06 & 0.223 \\
\hline & Work autonomy & 0.165 & 0.039 & $<0.001$ & 0.08 to 0.24 & \\
\hline & Peer support & 0.089 & 0.040 & $<0.05$ & 0.01 to 0.17 & \\
\hline & Supportive supervision & -0.19 & 0.096 & $<0.05$ & -0.38 to -0.00 & \\
\hline Social prestige & Work autonomy & 0.153 & 0.032 & $<0.001$ & 0.09 to 0.22 & 0.124 \\
\hline \multirow[t]{3}{*}{ Self-efficacy } & Workload & -0.204 & 0.082 & $<0.01$ & -0.37 to 0.04 & 0.436 \\
\hline & Work autonomy & 0.185 & 0.042 & $<0.001$ & 0.10 to 0.27 & \\
\hline & Peer support & 0.089 & 0.040 & $<0.05$ & 0.01 to 0.17 & \\
\hline Relatedness & Work autonomy & 0.238 & 0.036 & $<0.001$ & 0.17 to 0.31 & 0.276 \\
\hline \multirow[t]{7}{*}{ Intrinsic job satisfaction } & Workload & -0.097 & 0.039 & $<0.01$ & -0.18 to -0.02 & 0.510 \\
\hline & Work autonomy & 0.215 & 0.020 & $<0.001$ & 0.17 to 0.25 & \\
\hline & Healthcare infrastructure & -0.145 & 0.049 & $<0.001$ & -0.24 to -0.05 & \\
\hline & Work modality & -0.063 & 0.030 & $<0.05$ & -0.12 to 0.05 & \\
\hline & Training & 0.327 & 0.038 & $<0.001$ & 0.25 to 0.40 & \\
\hline & Supportive supervision & -0.229 & 0.079 & $<0.001$ & -0.38 to -0.07 & \\
\hline & Peer support & 0.131 & 0.045 & $<0.001$ & 0.04 to 0.22 & \\
\hline
\end{tabular}

We have more support from our Didis and women's groups are now more enthusiastic and capable in community activities. Our social cohesion is improving further. [CHW, \#4]

Supporting the survey data, many reported enhancement in their family and social status, and personal autonomy attributing to the role of CHW. They felt empowered through the acquisition of knowledge and skills on community health through training, designated stature in the community and the personal autonomy to work. Peer support and healthy competition among the ASHAs seemed to have enhanced their enthusiasm to perform well and achieve progressive community health. They enjoyed the job autonomy to perform the designated duties.

Now I have a say in my neighborhood. I am being invited to sit in community meetings and I represent my village in health centre meetings. [CHW\# 28]

We meet during trainings and meetings and share a lot with each other. Since we have the same kind of work, learning from each other has increased our problemsolving skills. [CHW \# 41]

\section{Demotivating factors}

On the contrary, the CHWs had certain dissatisfactions on certain health system aspects limiting their performance motivation at the individual and the community levels. Excessive workload, frequent refresher trainings and meetings at health centres and travel to remote habitations took away their personal time. They sometimes felt having limited autonomy at work to perform their social responsibilities beyond the specified guidelines. The CHWs solicited their active involvement in the planning of service delivery to incorporate community's felt needs, as often they were given only the options to deliver services than planning.

Very often what the programme wants and people want from me are different. I feel whatever issues I raise on behalf of the community during the health centre meetings are not addressed timely. [CHW\# 74]

Many posed concern on the community's lack of trust on the public healthcare system. There were instances of care seeking from the private informal providers, despite the availability of drugs with the CHWs. This community behaviour was built on the instances of them not getting drugs from the CHWs due to unavailability. Their activities were limited by the frequent stock-out of drugs and commodities and the communication gap at different levels of their supervision.

They also reported to have an inadequate level of knowledge, skills and supportive supervision to perform optimally. Their performances were monitored through the self-recording of activities, supplemented with random visits by the multipurpose female health workers and other supervisors. They found it difficult to monitor community health through surveys as it was time consuming and tricky to record, with their low level of education. Most of them expected to have routine supportive supervision of their activities and the grass-roots level organisations' cooperation to enable improved performances.

We would like to have an integrated approach with the women's group, the NGOs and the village health committee to share and solve local issues. [CHW\# 13] 
Often, I communicate timely on drug stock-outs to subcentre, but the primary health centres tell that they are not aware of this. I feel my concerns and issues are not spelled out at the higher level properly, though I share everything with my supervisors. I am also not given timely instruction on my roles on many activities [CHW \#53]

They demanded for more flexibility in organising meetings at convenient locations to give more time for the community and their personal life. Although CHWs received honorarium for trainings and meetings, they did not prefer frequently attending them. They were confident to execute the responsibilities, still desired knowledge and skill enhancement to convince the community and gain community acceptance. They seemed to be less confident on curative skills and urged for more system thrust and training in this regard.

I want to be with the community more than the meetings. We wait for longer time, even for four hours at the health centres for a one hour meeting [CHW\# 29]

Some of them were disgruntled on the level of the monetary and ours non-monetary incentives received, yet they did not want to underperform. The ASHAs often had to expend on mother's consumables and spare on an average 30 hours on escorting mothers for child birth. However what they receive was lesser considering their actual spending and the time cost. They denied having any opportunity for informal payments, but admitted to have received occasional incentives for escorting mothers without actually doing so.

I often spend out-of-pocket on mother's consumables at hospitals and what I receive is quite less in return. Still, I want to support mothers as I feel they are like my sisters and I am obliged to support them. [CHW\#69]

\section{DISCUSSION \\ What prompts the CHWs to perform and its externalities on community health?}

The rural women consider becoming a CHW as a magnificent opportunity to empower themselves socially, personally and financially. ${ }^{16}$ Empowering rural women as CHWs, who do not have alternate job opportunities can be a replicable and sustainable model on community health management. ${ }^{17}$ In this study, the level of motivation was directly related to self-efficacy, yet socioeconomic status did not influence the latter. This implies that with proper selection, orientation and training, the lay women can be organised for community health activities. $^{18-21}$

They displayed a strong commitment towards empowering women as women were more receptive to their advices. The higher level of health awareness and adherence to healthy practices among women compared to men might justify this village-level social network among women. ${ }^{22}$

The identity with the government motivated them to be a bridge between the community and the public healthcare system. This will be relevant for those countries trying to reduce the poor people's dependency on the private sector. ${ }^{1}$ Peer support and cross-learning from peers were potential ways of inspiration, apart from the support of many community-based organisations. The involvement of locally based NGOs and communitybased organisations needs to be promoted to empower and support the CHWs. ${ }^{23}$ However, the NGOs need to be a complimentary mechanism and should not undermine the CHWs' efficiency as health workers. ${ }^{24}$

Above all, a sense of intrinsic motivation was the underlying factor for the CHWs' performance. For instance, their urge for community interactions prevented them from attending the meetings and training, despite the scope of receiving honoraria in such events. The local cultural traits of solidarity, hospitality and providing social support lifted their enthusiasm. ${ }^{25}$ These behavioural traits could be exploited positively with providing more public recognition to the CHWs. The events of 'public honoring', involvement in public meetings and appreciation in their group meetings would be an impetus for their social commitment. Kenya also reported on CHWs' strong preference for community acceptance compared to the supervisor's recognition. ${ }^{5}$

In this study, the CHWs' dissatisfaction on remuneration was not associated with their level of earning. This implies that remuneration through incentivising each activity seems to have motivated performance despite their feeling of under-remunerated. Yet, care should be taken to ensure that the CHWs perform equally on all the responsibilities despite the incentives varying on each responsibility. Further, they should be remunerated adequately considering the time cost and the market rate.

\section{What discourages the CHWs and the consequences?}

The study found a strong nexus between the healthcare delivery system's status and the CHW's level of performance motivation. As demonstrated in similar settings, resource constraints such as limited transportation to escort mothers and stock-outs of commodities hindered the community's trust on them. ${ }^{26}$ The communication gap among different actors led to delay in receiving the stocks and non-clarity on the responsibilities among CHWs. This weak supportive system to $\mathrm{CHWs}$ concerns many other countries also as it might lead to the exclusion of the poorest of the poor from appropriate health services. $^{1}$

The CHWs demanded for regular supportive supervision and streamlining of responsibilities. However, in resource-constraint settings, identifying and training more experienced volunteers for CHW's supervision will be a challenge. This concern should be addressed through leveraging some of the grass-roots level public health managers or NGOs in a systematic manner. More involvement of grass-roots entities like women's groups could inculcate a sense of collective accountability and learning. Nigeria reported village health committee (VHC) supporting CHWs. ${ }^{27}$ Since India's VHCs are still 
evolving, CHW's monitoring can be designed as one of its roles in future. ${ }^{19}$

The CHWs' increasing work load with more and more community-based health programmes produced a feeling of 'overburdened'. Without proper orientation, monitoring of many community health initiatives, especially surveys will be difficult for them, considering their low level of formal education. ${ }^{28}{ }^{29}$ Though the current pattern of incentivising does not appear to bring in less performance, India could experiment with preferential treatment on social securities and public privileges to the CHWs and their households as demonstrated in Guatemala and Nepal. ${ }^{27}$

In India, the ASHAs are more indentified as 'linkworkers' or facilitators for appropriate care and the community has less acceptance for their curative role. ${ }^{7}$ The CHWs are less confident on their curative care skills and the supply constraints induce the community's nonconfidence on them. ${ }^{30-32}$ In future, the CHWs' could be leveraged intensively on diagnosing health conditions to promote a comprehensive community health management approach. This will be relevant for elderly care and settings with increasing chronic disease burden to offer a cost-effective care. ${ }^{19} 33-35$

\section{Strengths and limitations of the study}

We employed a mixed-methods approach and it helped us in two ways. First, to understand the extent of causality between the CHW's level of motivation and each of its determinant. Second, to assess how, why and under what condition a CHW is motivated or demotivated. The study depended on a 'relativist' approach to trigger the policy processes on streamlining the motivating factors for the CHW's performance motivation. Further, the FGD responses were used to verify the survey responses and thereby enhance the generalisability of the study outcomes. There could be a possibility of the CHWs' responses complying with the perceptions of what should be an acceptable answer. We did not assess the actual level of performance of the CHWs and its effectiveness from the community's or supervisors' perspectives. Despite this, these study revelations on the CHW programme add to the rare global evidence base for relevant policy changes, specifically on the CHW management and the retention.

\section{CONCLUSION}

The CHW programme could motivate and empower the local lay women on community health largely. The desire to gain social recognition, a sense of social responsibility and self-efficacy enhances their motivation. Linking the incentive directly with each activity ensures performances of the CHWs. The healthcare delivery system improvement might further enhance their motivation and enable them to gain the community trust. The CHW management needs to change with adequate supportive supervision, skill and knowledge enhancement and enabling working modalities.

Acknowledgements We are thankful to all the community health workers, participated in the study. We also thank the women's groups, who mobilised the study participants. We are grateful to the editorial board and the reviewers for their comments on an earlier version of the manuscript.

Contributors All authors took part in the conceptualisation, design of tools and writing of manuscript. SSG analysed the data and wrote the first draft of the manuscript. SNM enabled the data collection. All authors read and approved the final version.

Competing interests None.

Patient consent Obtained.

Provenance and peer review Not commissioned; externally peer reviewed.

Data sharing statement We declare that all the raw data are available with the primary authors on the published information for public sharing.

Declaration The opinions expressed in this paper are exclusively of the authors and not of their organizations they are currently affiliated with.

\section{REFERENCES}

1. World Health Organization. Health systems financing-the path to universal coverage. Geneva: World Health Report, 2010.

2. Lehmann U, Sanders D. Community health workers: what do we know about them? The state of the evidence on programmes, activities, costs an impact on health outcomes of using community health workers. Geneva: The World Health Organization, 2007.

3. Lewin S, Munabi-Babigumira S, Glenton C, et al. Lay health workers in primary and community health care for maternal and child health and the management of infectious diseases. Cochrane Database Syst Rev 2010;(3): CD004015.

4. Shrestha R, Baral K, Weir N. Community ear care delivery by community ear assistants and volunteers: a pilot programme. J Laryngol Otol 2003;115:869-73.

5. Lewin SA, Dick J, Pond P, et al. Lay health workers in primary and community health care. Cochrane Database Syst Rev 2005;(1): CD004015.

6. Glenton C, Inger BS, Pradhan S, et al. The female community health volunteer programme in Nepal: Decision makers' perceptions of volunteerism, payment and other incentives. Soc Sci Med 2010;70:1920-7

7. Government of India. ASHA the way forward: evaluation of ASHA program. NRHM New Delhi: The National Health System Resource Center, 2011.

8. Dieleman M, Cuong PV, Anh LV, et al. Identifying factors for job motivation of rural health workers in North VietNam. Hum Resour Health 2003;1:10.

9. Mbindyo P, Gilson L, Blaauw D, et al. Contextual influences on health worker motivation in district hospitals in Kenya. Implement Sc 2009;4:43; doi:10.1186/1748-5908-4-43.

10. Darmstadt GL, Baqui $\mathrm{AH}$, Choi $\mathrm{Y}$, et al. Validation of community health workers' assessment of neonatal illness in rural Bangladesh. Bull World Health Organ 2009;87:12.

11. Rahman SM, Ali NA, Jennings $L$, et al. Factors affecting recruitment and retention of community health workers in a newborn care intervention in Bangladesh. Hum Resour Health 2010;8:12 http:// www.human-resources-health.com/content/8/1/12 (accessed on 24th November 2011).

12. Li I-C, Lin M-C, Chen C-M. Relationship between personality traits, job satisfaction, and job involvement among Taiwanese community health volunteers. Public Health Nurs 2007;24:274-82.

13. Government of India. Accredited Social Health Activist (ASHA) guidelines, National Rural Health Mission. New Delhi: Ministry of Health and Family Welfare, 2005.

14. Government of India. Annual report: 2009-10. New Delhi: Ministry of Health and Family Welfare, 2010. http://mohfw.nic.in/Health\% 20English\%20Report.pdf (accessed on 11th July 2011).

15. Manongi RN, Marchant TC, Bygbjerg IBC. Improving motivation among primary health care workers in Tanzania: a health worker perspective. Hum Resour Health 2006;4:6; doi:10.1186/ 1478-4491-4-6.

16. Willis-Shattuck M, Bidwell $P$, Thomas $S$, et al. Motivation and retention of health workers in developing countries: a systematic review. BMC Health Serv Res 2008;8:247. 
17. Willis-Shattuck M, Bidwell P, Thomas S, et al. Motivation and retention of health workers in developing countries: a systematic review. BMC Health Serv Res 2008;8:247.

18. Scott K, Shanker S. Tying their hands? Institutional obstacles to the success of the ASHA community health worker programme in rural north India. AIDS Care 2010;22:1606-12.

19. Kane SS, Gerretsen B, Scherpbier R, et al. A realist synthesis of randomised control trials involving use of community health workers for delivering child health interventions in low and middle income countries. BMC Health Serv Res 2010;10:286.

20. Daniels K, Van Zyl HH, Clarke M, et al. Ear to the ground: listening to farm dwellers talk about the experience of becoming lay health workers. Health Policy 2005;73:92-103.

21. George A. Nurses, community health workers, and home carers: gendered human resources compensating for skewed health systems. Glob Public Health 2008;3:75-89.

22. Gopalan SS. Report on health equity. Bhubaneswar: Government of Orissa, DoHFW, 2009

23. Gray $\mathrm{HH}$, Ciroma J. Reducing attrition among village health workers in rural Nigeria. Soc Econ Plann Sci 1988;22:39.

24. Kironde S, Klaasen S. What motivates lay volunteers in high burden but resource-limited tuberculosis control programmes? Perceptions from the Northern Cape province, South Africa. Int J Tubercul Lung Dis 2002;6:104.

25. Robinson SA, Larsen DE. The relative influence of the community and the health system on work performance: a case study of community health workers in Colombia. Soc Sci Med 1990;30:1041.

26. Baker B, Benton D, Friedman E, et al. Systems support for task shifting to community health workers. Geneva: The Global Health Alliance, 2007.
27. Bhattacharya $\mathrm{K}$, Winch $\mathrm{P}$, LeBan $\mathrm{K}$, et al. Community health worker incentives and disincentives: how they affect motivation, retention and sustainability. Basics // 2001;2:1-68.

28. Abbatt F. Scaling up health and education workers: community health workers: a literature review. London: DFID Health Systems Resource Centre, 2005

29. Henderson L, Tulloch J. Incentives for retaining and motivating health workers in Pacific and Asian countries. Hum Resour Health 2008;6:18.

30. Wendy Gidman W, Ward P, McGregor L. Understanding public trust in services provided by community pharmacists relative to those provided by general practitioners: a qualitative study. BMJ Open 2012;2:e000939; doi:10.1136/bmjopen-2012-000939.

31. Nyanzi S, Manneh H, Walraven G. Traditional birth attendants in rural Gambia: beyond health to social cohesion. Afr J Reprod Health 2007; 11:43-56.

32. Khan SH, Chowdhury AM, Karim F, et al. Training and retaining Shasthyo Shebika: reasons for turnover of community health workers in Bangladesh. Health Care Superv 1998;17:37-47.

33. Palmas W, Teresi JA, Findley S, et al. Protocol for the Northern Manhattan Diabetes Community Outreach Project. A randomised trial of a community health worker intervention to improve diabetes care in Hispanic adults. BMJ Open 2012;2:e001051; doi:10.1136/ bmjopen-2012-001051.

34. Macinko J, De Fátima Marinho de Souza M, Guanais FC, et al Going to scale with community-based primary care: an analysis of the family health program and infant mortality in Brazil, 1999e2004. Soc Sci Med 2007;65:2070-2080.

35. Robert J, Blendon RJ, Benson JM, , et al A four-country survey of public attitudes towards restricting healthcare costs by limiting the use of high-cost medical interventions. BMJ Open 2012;2:e001087; doi:10.1136/bmjopen-2012-001087. 